\title{
Some effects of injections of ribonucleic acid'
}

\author{
JOHN A. CORSON AND HILDEGARD E. ENESCO
}

MCGILL UNIVERSITY

A series of experiments examined the effect of intraperitoneal injections of yeast RNA on the behavior of rats in various situations. Animals injected with RNA were superior to control animals in a task involving climbing a pole to es cape shock. There were no significant differences in other shock motivated learning tasks, open field activity, strength or endurance, or basal metabolic rate. Evidence was considered which suggests that any effects of intraperitoneal RNA injections would be mediated primarily by processes taking place outside of the brain.

Yeast ribonucleic acid (RNA) was first mentioned as having beneficial effects on memory by Cameron and co-workers $(1961,1963)$ who reported that RNA administered in tablet form or by intravenous injection produced clinical improvement in patients suffering from senile memory impairment. This effect was later studied by Cook et al (1963) who showed that yeast RNA (160 $\mathrm{mg} / \mathrm{kg}$ I.Po) increased the rate at which rats learn the response of climbing a pole to escape shock. Recently, however, the suggestion that RNA produces a general improvement in learning or memory processes has been questioned by Wagner et al (1966). These workers repeated the experiment reported by Cook etal and obtained essentially the same results. They then went on to test the effects of yeast RNA injections on learning of a food motivated brightness discrimination, on shock sensitivity and on general activity and found that RNA did not change performance in these situations. Similarly, Luttges et al (1966) have shown that rats injected with rat brain RNA were not superior to a saline injected control group in various learning situations, including a water " $\mathrm{Y}$ " maze and a Lashley III maze.

Luttges et al also found that IP injections of $\mathrm{P}^{32}$ labeled RNA did not result in significant amounts of radioactivity being found in the brain. This result has also been obtained by Sved (1965), and by Eist \& Seal (1965) using a tracer technique, and by Enesco (1966), using radioautography, and suggests that any effects of exogenous RNA are not due to a direct incorporation of RNA into brain tissue.

The present study was undertaken in an attempt to determine the basis of the effect of RNA injections on shock motivated pole-climbing behavior and to examine the effects of these injections on behavior in other situations.

\section{Experiment 1}

The Ss were 15 adult male hooded rats, weighing 200-240 gm, obtained from the Quebec Breeding Farms. A group of five animals received intraperitoneal injections of $160 \mathrm{mg} / \mathrm{kg}$ yeast $\mathrm{RNA}$ (Pabst Laboratories) in $10 \%$ neutral solution. A second group of five animals received $40 \mathrm{mg} / \mathrm{kg}$ of uric acid, a metabolic product of RNA. The five remaining animals were injected with saline and served as controls. Injections were started 20 days prior to experimentation and were continued daily at 5 p.m. during the experimental period.

The Ss were required to learn a spatial discrimination and reversal in an electrified two-choice discrimination box which was divided into five sections: start area, choice area, two threshold areas and a goal area. All but the goal area had grid floors which could be electrified by the experimenter. A detailed description of the apparatus and technique has been given elsewhere (Corson, 1965). On the first training day the Ss learned to go quickly from the start to the goal (the start grid was electrified at 5 sec. and all grids were electrified at 30 sec.), through either door, to avoid shock. Having reached a criterion of three consecutive unshocked runs, they then learned to enter the goal by crossing the threshold area on one side. During this phase the incorrect door was locked and its threshold area was electrified. On the following day, the opposite door was correct.

The results show that neither of the experimentas groups was different from the controls in any of the measures taken (start latency, total latency, number of trials to criterion in each phase, and number of errors in each phase). The Mann-Whitney U test (two-tailed) was used in all cases.

It is important to note that the first phase of this experiment, when the animals had not yet learned to avoid shock, was a simple escape task similar to that used by Cook et al except that the animals were running to the goal end of the apparatus to escape shock instead of climbing a pole. The fact that RNA-injected animals were not superior in this escape task suggests that the response required of the animal is an important variable. Experiment 2

The second experiment used the previously described Ss and apparatus and was begun on the 24 th injection day. The Ss were required to learn a discrimination between horizontal and vertical black and white stripes which were painted on cards placed on the doors to the goal area. These cards were alternated in a prearranged random order from one door to the other. One card was always placed on the unlocked door, while the other was always on the locked door. The threshold area in front of the locked door was always electrified. The Ss were given 15 trials per day for two days and then 10 trials per day for three days. Again, there were no differences between any of the injection groups in any of the measures taken.

\section{Experiment 3}

The third experiment examined the open field activity of the animals used in Experiments 1 and 2. On the 36th injection day each animal was placed alone in a 42-in. square which was marked off into 25 equal sections. Activity during a $15 \mathrm{~min}$. period was recorded by an observer. The results show no differences in number of squares entered, temporal points of maximum and minimum activity or in activity changes in response to sudden onset of a loud buzzer.

\section{Fxperiment 4}

Again using the same Ss, the fourth experimentbegan 
on the 56th injection day and was an attempt to replicate the study of Cook et al (1963). The results show that the animals given injections of RNA made fewer errors during acquisition of the pole-climbing response $(\mathrm{p}<.05$ two-tailed test) and made more responses when shock was no longer being given ( $p<.05$ two-tailed test). Cook et al found, after all animals had reached the $100 \%$ level of performance, that the response latencies for the animals injected with RNA were about half as long as those of the saline animals. This result was not found in the present experiment. Our failure to find this latency difference may be due to the considerable experience with shock escape and avoidance which our Ss gained during the first two experiments.

A variation of this experiment was begun on the 88th injection day which involved turning on the shock for $5 \mathrm{~min}$. and recording how long during this period the $\mathrm{S}$ was able to hold onto the pole. This was done to see if the results of the pole-climbing experiment were produced by strength or endurance differences resulting from the RNA injections. The $5 \mathrm{~min}$. period was long enough to be a real test of endurance since the longest any animal was able to stay on the pole was $2 \mathrm{~min}$. at a time, and less than $4 \mathrm{~min}$. total. The results for the first day of this experiment show that the animals in the RNA group tended to climb the pole more quickly ( $p<.10$ two-tailed test) and to spend more time holding onto the pole $(p<.10$ two-tailed test). This procedure was repeated for three more days, and on these days no further suggestion of such differences was noticed. These results show that the difference found in the pole-climbing experiment was not simply a strength or endurance difference and supports the suggestion made by Wagner et al (1966) that the RNA injections may produce an increase in the untrained likelihood of pole-climbing in response to shock.

\section{Experiments 5, 6, 1 and 8}

Other investigations using rats as Ss have shown that yeast RNA injections produced a higher rate of bar-pressing for water (Solyom et al, 1966) and a lower number of trials taken to learn a $T$ maze for food (Goren, 1965). Similar effects have been produced by drugs which stimulate the central nervous system (Barry et al, 1963; McGaugh \& Petrinovitch, 1959). These experiments were done to see if the effect of caffeine injections would be comparable to that of RNA injections. The $\mathrm{Ss}$ were 20 rats of the same description as those in the first four experiments. One group of five animals was injected with 8 $\mathrm{mg} / \mathrm{kg}$ caffeine and another group of five animals was injected with $\neq \mathrm{mg} / \mathrm{kg}$ caffeine. The remaining 10 animals served as saline injected controls. All injections were given $1-2 \mathrm{hr}$, before testing began.

These experiments used the same technique as the first four and none of the results reach acceptable levels of significance. However, there was a tendency for both groups of caffeine injected Ss to be poorer than the saline Ss on the pattern disurimination and for the Ss injected with $4 \mathrm{mg} / \mathrm{kg}$ caffeine to be better in climbing the pole (in both cases $p<.20$ two-tailed test) during the original acquisition and extinction sessions, but not during the endurance sessions. Thus the idea that the effects of injections of RNA are comparable with those of brain stimulants is not well supported by these results.

\section{Experiment 9}

Records of water consumption and weight gain were kept during the first eight experiments and the results show that rats injected with RNA tend to gain weight less rapidly and to drink less water than those in any of the other groups ( $p<.10$ two-tailed test). This result suggested that there might be metabolic differences produced by the RNA injections which could be related to the differences in pole-climbing. To explore this possibility, 32 rats ranging from 280 to $380 \mathrm{gm}$ were divided with respect to body weight into groups of eight injected with RNA, seven injected with uric acid, 10 injected with $4 \mathrm{mg} / \mathrm{kg}$ caffeine and seven injected with saline. The injections were given daily for 6 months before testing began. The method described by Grad (1954) was used to measure basal metabolic rate and there were no significant differences among groups.

\section{Discussion}

These experiments (a) replicate the results of Cook et al and
Wamer et al, showing that RNA injections improve the performance of rats in a shock escape situation where $S$ is required to climb a pole, (0) show that RNA injections do not improve performance in a shock escape situation where $S$ is required to run to a safe place, (a) show that the RNA injections do not produce differences in general learning ability, strength or endurance, open field activity or basal metabolic rate, (d) show that the behavioral effects of injections of yeast RNA are not obtained with 4 or $8 \mathrm{mg} / \mathrm{kg}$ of caffeine, thus weakening the argument that the differences in performance in the pole-climbing situation are due to a brain stimulant activity of RNA. Since we have been unable to find another explanation for this effect, we agree with Wagner et al in concluding that one effect of injections of yeast RNA may be an increase in the untrained likelihood of poleclimbing in response to shock. We also agree that the basis of this effect remains obscure.

Turning to more general questions, we suggest that theoretical statements about the basis of the effects of injections of RNA should be re-evaluated. While the present results and those of the radioautography and tracer studies in no way exclude the possibility that a memory code may be carried by a special RNA fraction within the cell, they do strongly suggest that the relation of exogenous RNA to memory function is a basically different question from those involving intra-cellular RNA and problems of information coding in the brain. This conclusion also relates to the recent reports of transfer of tendencies (or responses or preferences) by injection of "educated RNA" (e.g., Jacobson et al, 1966), suggesting that any effects observed would be mediated primarily by processes taking place outside of
the brain.

\section{References}

Barry, H., Wagner, S. A., \& Miller, N. E. Effects of several drugs on performance in an approach-avoidance conflict. Psychol. Rep., 1963, 12, 215-221.

Cameron, D. E., \& Solyom, L. Effects of ribonucleic acid on memory. Geriatrics, $1961,16,74-81$.

Cameron, D. E., Sved, S., Solyom, L., Wainrib, B., \& Barik, H. Effects of ribonucleic acid on memory defect in the aged. Amer. J. Psychiat., 1963, 120, 320-325.

Cook, L., Davidson, A. B., Davis, D. J., Green, H., \& Fellows, E. J. Ribonucleic acid: effect on conditioned behavior in rats. Science, 1963, 141, 263-269.

Corson, J. A. Memory as influenced by a singie electroconvulsive shock. J. Psychiat. Res., 1965, 3, 153-158.

Eist, H., \& Seal, U. S. The permeability of the blood-brain barrier and blood-CSF barrier to $\mathrm{C}^{14}$ tagged ribonucleic acid. Amer. J. Psychiat., 1965, 122, 584-586.

Enesco, H. E. Fate of $\mathrm{C}^{14}$-ribonucleic acid injected into mice. Exp. Cell Res., in press.

Goren, C. Ribonucleic acid: influence on the maze-learning ability of rats. Worm Runners Digest, 1965, 7, 28-31.

Grad, B. A simple method for the measurement of the oxygen consumption and heart rate of rats. Endocrinology, 1952, 50, 94-99.

Jacobson, A. L., Babich, F. R., Bubash, S., \& Goren, C. Maze preferences in naive rats produced by injections of ribonucleic acid from trained rats. Psychon. Sci., 1966, 4, 3-4.

Luttges, M., Johnson, T., Buck, C., Holland, J., \& McGaugh, J. An examination of "transfer of learning" by nucleic acid. Science, $1966,151,834-837$.

McGaugh, J., \& Petrinovitch, $\mathbf{L}$. The effect of strychnine sulphate on maze-learning. Amer. J. Psychol., 1959, 72, 99-102.

Solyom, L., Beaulieu, C., \& Enesco, H. E. Personal Communication, 1966.

Sved, S. The metabolism of exogenous ribonucleic acid injected into mice. Canad. J. Biochem., 1965, 43, 949-958.

Wagner, A. R., Carder, J. B., \& Beatty, W. W. Yeast ribonucleic acid: effects on learned behavior in the rat. Psychon. Sci., $1966,4,33-34$.

Note

1. This research was supported by Medical Research Council of Canada Grant MA 1746 and Dominion Provincial Mental Health Grant 604-7-499 and by Public Health Service Fellowship 2 F2 HD-25, 618-02 G+D. We thank Susanna Kertesz, Antoinette Kipman, Adrienne Spiegel and Hyman Rabinovitch for their assistance. 